\title{
Efeito de época de semeadura e adubação na mancha-foliar de Phaeosphaeria em milho(1)
}

\author{
Diego Girardi Pegoraro(2), Elton Vacaro(3), Claudio Natalino Nuss(3), Fábio Kessler dal Soglio(4), \\ Maria Jane Cruz de Melo Sereno ${ }^{(4)}$ e José Fernandes Barbosa Neto ${ }^{(4)}$
}

\begin{abstract}
Resumo - $\mathrm{O}$ aumento da área de cultivo de milho, aliado a algumas práticas culturais, tem favorecido o surgimento da mancha-foliar causada pelo fungo Phaeosphaeria maydis. Como conseqüência, o rendimento de grãos tem decrescido, especialmente em áreas com plantio direto e maior amplitude da época de semeadura. $\mathrm{O}$ trabalho teve como objetivo avaliar a severidade de $P$. maydis em seis híbridos de milho, em cinco épocas de semeadura e em dois níveis de adubação. O experimento foi conduzido em Xanxerê, SC, na safra 1997/98, em blocos casualizados, com parcelas subdivididas, em duas repetições. As plantas foram avaliadas 30 dias após o florescimento, e a porcentagem da área foliar afetada foi registrada. Na medida em que a semeadura do milho foi retardada, houve um aumento na severidade da moléstia e uma redução no rendimento de grãos. As doses de adubação não apresentaram diferença quanto à severidade da moléstia. $\mathrm{O}$ mês de setembro apresentou menor severidade da mancha-foliar e maior rendimento de grãos. Houve uma correlação significativa entre o rendimento de grãos e a severidade da moléstia.
\end{abstract}

Termos para indexação: Zea mays, Phaeosphaeria maydis, fatores ambientais, doenças das plantas.

\section{Effect of planting date and fertilization on Phaeosphaeria leaf blight in maize}

\begin{abstract}
The increase of the area cultivated with maize in Brazil, together with some cultural practices, has favored the severity of Phaeosphaeria leaf spot, caused by Phaeosphaeria maydis. As a consequence, grain yield decreased, especially in areas with late planting and zero tillage. The present work was planned to evaluate the severity of $P$. maydis in six maize hybrids, in five planting dates and fertilized in two different levels. The experiment was sowed in Xanxerê, SC, Brazil, during the 1997/98 season. Plants were evaluated 30 days after flowering and percentage of damaged leaf area was registered. The results indicated that as planting date was delayed, there was an increase in disease severity and a decrease in grain yield. Levels of fertilization did not affect disease severity. The September planting date showed the lowest Phaeosphaeria leaf spot severity and the largest grain yield. There was a significant correlation $(\mathrm{r}=0.45)$ between grain yield and severity of Phaeosphaeria maydis, indicating that the disease is an important factor to reduce grain yield.
\end{abstract}

Index terms: Zea mays, Phaeosphaeria maydis, environmental factors, plant diseases.

(1)Aceito para publicação em 10 de outubro de 2000 Extraído da Dissertação de Mestrado apresentada pelo primeiro autor à Universidade Federal do Rio Grande do Sul (UFRGS), Porto Alegre, RS.

(2) Fundação Pró-Sementes de Apoio à Pesquisa, Rua Diogo de Oliveira, 640, CEP 99025-130 Passo Fundo, RS. E-mail: dgpegoraro@hotmail.com

(3) Agroeste Sementes Ltda., Rua Antônio Vacaro 130 , CEP 89820-000 Xanxerê, SC. E-mail: evacaro@yahoo.com

(4) UFRGS, Caixa Postal 776, CEP 91501-970 Porto Alegre, RS. E-mail: fabiods@vortex.ufrgs.br, sereno@conex.com.br, jfbn@ufrgs.br

\section{Introdução}

Na cultura do milho (Zea mays L.), várias moléstias podem causar decréscimos expressivos no rendimento de grãos. Entre elas, a mancha-foliar de Phaeosphaeria (PLS) tem aumentado a incidência e a severidade nos últimos anos (Fernandes \& Oliveira, 1997). Até recentemente, essa moléstia era considerada secundária, por apresentar os sintomas na parte final do ciclo (Balmer \& Pereira, 1987). Entretanto, o aumento da área cultivada com o sistema de plantio direto e o cultivo de duas safras ao ano têm 
determinado um incremento na severidade da PLS, a qual pode causar perdas de, aproximadamente, $60 \%$ no rendimento de grãos em genótipos suscetíveis (Fernandes \& Oliveira, 1997).

O agente causal da PLS é o fungo Phaeosphaeria maydis (P. Henn.) Rane, Payak \& Renfro (sinônimo Sphaerulina maydis), cujo estágio anamórfico é Phyllosticta sp. (Reis \& Casa, 1996; Fernandes \& Oliveira, 1997). Os sintomas iniciam, em geral, com pequenas manchas levemente cloróticas nas folhas. No início, as lesões são aquosas de coloração verde-claro e com os bordos bem definidos de cor pardo-escuro (Fernandes \& Oliveira, 1997). Geralmente, os sintomas aparecem primeiro nas folhas inferiores, progredindo rapidamente para o ápice da planta. Normalmente, esses sintomas são manifestados após o florescimento.

Os fatores de ambiente, como o manejo da adubação, podem ser responsáveis pela predisposição de plantas ao ataque de patógenos (Bedendo, 1995). Da mesma forma, a intensificação do cultivo de milho em áreas irrigadas, com mais de uma safra por ano, pode permitir o acúmulo do inóculo do fungo no campo (Sawazaki et al., 1997). O aumento da área cultivada com o sistema de plantio direto também pode ser um fator que favorece o aumento da severidade da moléstia, uma vez que o fungo causador da PLS é necrotrófico, podendo permanecer nos restos culturais de plantas infectadas e incrementando o potencial de inóculo para anos posteriores (Reis \& Casa, 1996; Fernandes \& Oliveira, 1997).

No melhoramento genético de plantas é fundamental a identificação de variabilidade genética para a obtenção de progresso genético por meio da seleção. Assim sendo, a semeadura dos genótipos deve ser realizada em locais e em épocas que favoreçam o desenvolvimento do agente patogênico, possibilitando a distinção de níveis de resistência dos genótipos e de variabilidade genética existente no caráter.

O trabalho teve como objetivo avaliar a severidade da mancha-foliar de Phaeosphaeria em genótipos de milho em diferentes épocas de semeadura com dois níveis de adubação.

\section{Material e Métodos}

O trabalho foi realizado na Estação Experimental da Empresa Agroeste Sementes Ltda., localizada no Municí- pio de Xanxerê, SC, a $600 \mathrm{~m}$ de altitude. Foram utilizados seis híbridos comerciais de milho (AS523, AS32, AS3466, AS3477, AS3601 e AS140), sendo os dois primeiros híbridos duplos e os demais híbridos triplos, os quais foram semeados em cinco épocas, que variaram de setembro/1997 a janeiro/1998. As datas de semeadura foram 9/9/1997, 18/10/1997, 11/11/1997, 8/12/1997 e 9/1/1998, correspondendo da primeira à quinta época, respectivamente.

As doses de adubação constaram da aplicação de $300 \mathrm{e}$ $150 \mathrm{~kg} / \mathrm{h}$ a da fórmula N-P-K, 5-20-20. Foram aplicados em cobertura, no estádio V6 (Ritchie et al., 1999), 70 e $35 \mathrm{~kg} /$ ha de $\mathrm{N}$, respectivamente, na primeira e segunda dose de adubação.

O delineamento experimental utilizado foi o de blocos casualizados, com parcelas subdivididas em duas repetições. As parcelas principais receberam o tratamento de épocas de semeadura e doses de adubação e a subparcela, os híbridos testados. A unidade experimental foi constituída por quatro linhas de $5 \mathrm{~m}$ de comprimento com espaços de $0,80 \mathrm{~m} \times 0,50 \mathrm{~m}$ entre covas, e duas sementes por cova.

A avaliação visual de todos os híbridos quanto à severidade de PLS foi realizada aproximadamente 30 dias após o florescimento, o que corresponde ao estádio de crescimento R5 (Ritchie et al., 1999), onde dez plantas por parcela foram selecionadas ao acaso. A severidade foi considerada como a porcentagem da área foliar afetada pela moléstia. É importante destacar que a avaliação foi com base na infestação natural do fungo no campo. Os dados meteorológicos foram obtidos na Estação Meteorológica do Colégio Agrícola La Salle, situado no Município de Xanxerê, SC. Na colheita, o rendimento de grãos (kg/ha) foi medido e corrigido para a umidade padrão de $13 \%$. Os dados foram submetidos à análise de variância, e as médias separadas pelo teste de Tukey (Steel \& Torrie, 1980). Entre os caracteres severidade de PLS e rendimento de grãos foi estimado o coeficiente de correlação linear (Steel \& Torrie, 1980).

\section{Resultados e Discussão}

A análise dos dados permitiu identificar que apenas os fatores época de semeadura e genótipo e a interação época $\mathrm{x}$ genótipo foram significativos para a severidade da mancha-foliar de Phaeosphaeria (PLS) (Tabela 1). Por outro lado, todos os fatores individuais testados, assim como suas interações, foram significativos para o rendimento de grãos, exceto a interação adubação x genótipo e a interação tríplice. Os resultados demonstraram que a severidade da PLS 
depende da época em que a cultura do milho é semeada e dos genótipos utilizados. É importante destacar que a área utilizada para o experimento vinha sendo cultivada com milho durante cinco anos consecutivos, sem rotação de cultura, garantindo quantidades elevadas de inóculo em todas as parcelas.

$\mathrm{A}$ interação época de semeadura $\mathrm{x}$ genótipo foi significativa, porém seu quadrado médio foi reduzido quanto à severidade de PLS. Basicamente, essa interação foi causada por diferenças entre os híbridos em cada época de semeadura, e não modificou o posicionamento relativo dos genótipos. Dessa forma, os efeitos individuais do genótipo e, principalmente, da época da semeadura, desempenharam um papel fundamental na ocorrência da moléstia, sendo que o quadrado médio deste último fator foi superior aos demais (Tabela 1). Na medida em que a época da semeadura foi retardada, houve um incremento na

Tabela 1. Resumo da análise de variância das variáveis severidade à mancha-foliar de Phaeosphaeria e rendimento de grãos ( $\mathrm{kg} / \mathrm{ha}$ ) observados em genótipos de milho em diferentes épocas de semeadura e submetidos a dois níveis de adubação. Xanxerê, SC, 1997/98.

\begin{tabular}{lrcc}
\hline Causas de variação & GL & \multicolumn{2}{c}{ Quadrado médio } \\
\cline { 3 - 4 } & & Severidade & Rendimento de grãos \\
\hline Repetição & 1 & 52,2 & $39.772,0$ \\
Época (E) & 4 & $5.985,8^{* *}$ & $73.219 .917,3^{* *}$ \\
Adubação (A) & 1 & 100,5 & $3.731 .980,2^{* *}$ \\
Genótipo (G) & 5 & $749,4^{* *}$ & $5.032 .692,9^{* *}$ \\
E x A & 4 & 25,6 & $1.041 .865,6^{* *}$ \\
E x G & 20 & $79,5 * *$ & $688.185,0^{* *}$ \\
A x G & 5 & 10,1 & $314.075,1$ \\
E x A x G & 20 & 10,9 & $215.231,9$ \\
\hline CV (\%) & \multicolumn{3}{c}{8,6} \\
** Significar
\end{tabular}

severidade de PLS até a semeadura de novembro (Tabela 2). Quando a semeadura foi realizada em dezembro e janeiro, foi observada maior redução na severidade da moléstia em comparação com a de novembro; entretanto, o grau dessa severidade foi superior ao da observada na semeadura efetuada em setembro-outubro. Brasil \& Carvalho (1998) obtiveram resultados similares, sendo que a época de semeadura foi um fator preponderante na redução do rendimento de grãos e no aumento da severidade da moléstia. Na semeadura do mês de janeiro, foi possível identificar sintomas da moléstia em plantas jovens. Provavelmente, a ocorrência de fatores de ambiente favoráveis ao desenvolvimento do fungo durante os meses de janeiro e fevereiro permitiu a manifestação precoce dos sintomas. Nas regiões produtoras de milho do Estado de São Paulo tem sido verificada uma predominância maior da moléstia nos meses de dezembro a março (Sawazaki et al., 1997). Por outro lado, Fernandes \& Oliveira (1997) afirmam que, geralmente, a severidade da moléstia no Brasil aumenta a partir do mês de novembro.

A avaliação da severidade da PLS foi realizada no período reprodutivo; dessa forma, a maior ocorrência de moléstia observada na semeadura do mês de novembro pode ser explicada pelas condições de ambiente favoráveis, especialmente de temperatura e umidade observadas em janeiro e fevereiro (Figura 1). A severidade da PLS é favorecida pela umidade relativa do ar acima de $60 \%$ e por temperaturas noturnas em torno de $14^{\circ} \mathrm{C}$ (Balmer \& Pereira, 1987; Menten et al., 1996; Fernandes \& Oliveira, 1997). As condições meteorológicas ocorridas durante o transcorrer do experimento foram de temperaturas moderadas e alta umidade relativa do ar, sendo os

Tabela 2. Severidade da mancha-foliar de Phaeosphaeria (em \% de área foliar afetada) observada em seis híbridos de milho, em diferentes épocas de semeadura. Xanxerê, SC, 1997/98(1).

\begin{tabular}{|c|c|c|c|c|c|c|c|}
\hline \multirow[t]{2}{*}{ Época } & \multicolumn{6}{|c|}{ Genótipo } & \multirow[t]{2}{*}{ Média } \\
\hline & AS32 & AS3466 & AS3477 & AS140 & AS3601 & AS523 & \\
\hline Setembro & $19,5 \mathrm{E}$ & $5,9 \mathrm{~B}$ & $8,1 \mathrm{E}$ & $8,3 \mathrm{D}$ & $8,9 \mathrm{E}$ & $10,1 \mathrm{E}$ & $10,1 \mathrm{E}$ \\
\hline Outubro & $24,8 \mathrm{D}$ & $6,5 \mathrm{~B}$ & $12,9 \mathrm{D}$ & $12,9 \mathrm{C}$ & $13,1 \mathrm{D}$ & $15,6 \mathrm{D}$ & $14,3 \mathrm{D}$ \\
\hline Novembro & $61,5 \mathrm{~A}$ & $31,8 \mathrm{~A}$ & $39,7 \mathrm{~B}$ & $48,5 \mathrm{~A}$ & $57,9 \mathrm{~A}$ & $58,6 \mathrm{~A}$ & $49,8 \mathrm{~A}$ \\
\hline Dezembro & $46,7 \mathrm{~B}$ & $33,3 \mathrm{~A}$ & $43,5 \mathrm{~A}$ & $42,6 \mathrm{~B}$ & $53,5 \mathrm{~B}$ & $50,1 \mathrm{~B}$ & $44,9 \mathrm{~B}$ \\
\hline Janeiro & $38,5 \mathrm{C}$ & $15,2 \mathrm{~B}$ & $22,9 \mathrm{C}$ & $42,2 \mathrm{~B}$ & $30,8 \mathrm{C}$ & $35,5 \mathrm{C}$ & $30,9 \mathrm{C}$ \\
\hline Média & $38,2 \mathrm{a}$ & $18,5 \mathrm{e}$ & $25,4 d$ & $30,9 c$ & $32,7 b c$ & $34,2 b$ & \\
\hline
\end{tabular}

${ }^{(1)}$ Médias seguidas pela mesma letra, maiúscula nas colunas e minúscula nas linhas, não diferem entre si pelo teste de Tukey a $5 \%$ de probabilidade 
meses de janeiro e fevereiro especialmente favoráveis para o desenvolvimento da moléstia (Figura 1). A umidade relativa do ar permaneceu ao redor dos $80 \%$ durante todo o experimento. Por outro lado, a temperatura média diurna foi mais elevada nos meses de janeiro e fevereiro; sem, entretanto, atingir níveis muito elevados, permanecendo na faixa de $20^{\circ} \mathrm{C}$ a $30^{\circ} \mathrm{C}$. Da mesma forma, a temperatura noturna foi mais elevada nos meses de janeiro e fevereiro, permanecendo na faixa de $10^{\circ} \mathrm{C} \mathrm{a} 15^{\circ} \mathrm{C}$, o que favoreceu o desenvolvimento do patógeno. Em três locais, Sawazaki et al. (1997) observaram maior severidade da moléstia no local de maior umidade do ar e com temperatura moderada.

Todos os híbridos avaliados apresentaram comportamento similar em relação à época de semeadura; no entanto, foi possível verificar uma ampla variabilidade quanto ao nível de resistência entre eles (Tabela 2). O híbrido AS3466 foi o mais resistente em todas as épocas de semeadura, e o genótipo AS32, o mais suscetível. Resultados similares foram obtidos com híbridos comerciais de milho (Fantin, et al., 1991; Menten et al., 1996; Sawazaki et al., 1997; Brasil \& Carvalho, 1998), o que sugere que a espécie apresenta elevada variabilidade genética para o caráter. Da mesma forma, Carson (1999) verificou diferenças na severidade de PLS em linhagens americanas per-

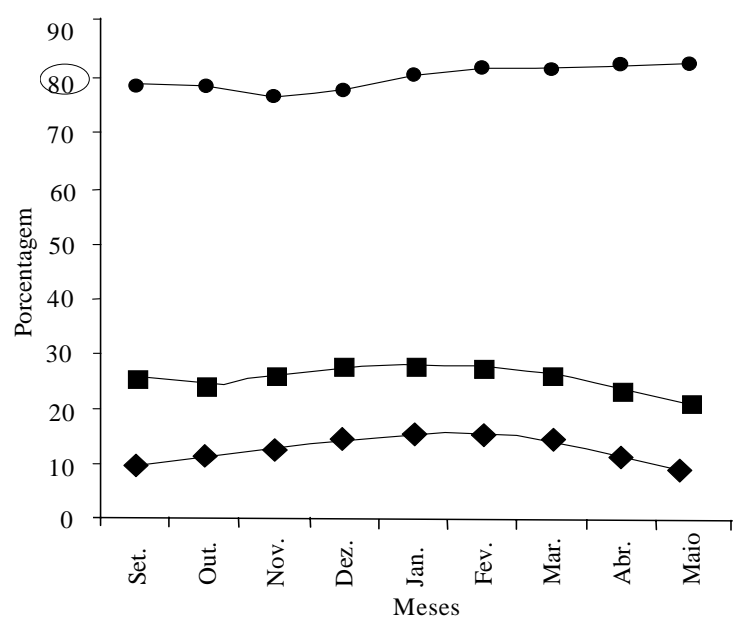

Figura 1. Umidade relativa do ar (๑, \%) e temperaturas médias diurnas $\left(\boldsymbol{\square},{ }^{\circ} \mathrm{C}\right)$ e noturnas $\left(\bullet,{ }^{\circ} \mathrm{C}\right)$ observadas em Xanxerê, SC, de setembro/1997 até maio/1998. tencentes a diferentes grupos heteróticos, onde as linhagens ligadas ao grupo B73 foram as mais suscetíveis.

Fatores associados ao solo e às técnicas culturais podem ser responsáveis pela predisposição de plantas ao ataque de patógenos (Bedendo, 1995). Uma das grandes mudanças nas lavouras de milho foi a introdução de algumas técnicas que atenuam as perdas de solo causadas pela erosão e que deixam grande quantidade de resíduos sobre o solo. O acúmulo desses resíduos pode aumentar a incidência e a severidade de alguns fungos necrotróficos. Nazareno et al. (1993) observaram diferenças quanto à severidade da mancha-foliar de cercóspora na medida em que a quantidade de resíduo sobre o solo aumentava. Por outro lado, Ward et al. (1997) não encontraram diferenças na severidade da manchafoliar de cercóspora para diferentes tipos de preparo do solo quando o nível de infecção era elevado. O nível de fertilidade do solo é outro fator importante para a predisposição das plantas às moléstias. A adubação nitrogenada tem sido apontada como fator que pode contribuir para aumentar a severidade de moléstias foliares e de solo (Mackenzie, 1981; Moorman, 1986; Huber \& McCay-Buis, 1993). Com relação à PLS, não existem informações disponíveis sobre os efeitos da adubação na severidade da moléstia. No presente trabalho, não foi identificada diferença entre os níveis de fertilizantes aplicados. Provavelmente, esses dois níveis não causaram nutrição desbalanceada nas plantas, as quais não apresentaram predisposição diferencial para PLS.

Houve diferença entre as doses de adubação utilizadas, onde o maior rendimento de grãos foi obtido com a maior dose (Tabela 3). É importante salientar que a menor dose de adubação já foi adequada, em virtude da fertilidade natural do solo, e da adubação que é realizada todos os anos. Na menor dose, a semeadura de setembro apresentou o maior rendimento de grãos, e na medida em que a semeadura foi retardada houve um decréscimo neste caráter. A maior dose demonstrou resultados similares, porém não houve diferença no rendimento de grãos nas semeaduras dos meses de setembro e outubro. O decréscimo no rendimento de grãos com o atraso na semeadura evidencia que épocas tardias não são indicadas para a cultura do milho na região. 
Tabela 3. Rendimento de grãos ( $\mathrm{kg} / \mathrm{ha}$ ) de seis híbridos de milho em diferentes épocas de semeadura e submetidos a dois níveis de adubação. Xanxerê, SC, 1997/98(1).

\begin{tabular}{|c|c|c|c|c|c|c|c|}
\hline \multirow{2}{*}{ Época } & \multicolumn{6}{|c|}{ Genótipo } & \multirow{2}{*}{ Média } \\
\hline & AS32 & AS3466 & AS3477 & AS140 & AS3601 & AS523 & \\
\hline \multicolumn{8}{|c|}{ Menor dose ${ }^{(2)}$} \\
\hline Setembro & $7.243 \mathrm{a}$ & $7.571 \mathrm{a}$ & $7.182 \mathrm{a}$ & $7.461 \mathrm{a}$ & $7.781 \mathrm{a}$ & $7.451 \mathrm{a}$ & $7.449 \mathrm{a}$ \\
\hline Outubro & $6.045 b$ & $7.115 \mathrm{ab}$ & $6.819 \mathrm{a}$ & $5.406 \mathrm{~b}$ & $6.709 \mathrm{~b}$ & $6.170 \mathrm{~b}$ & $6.377 b$ \\
\hline Novembro & $5.702 b$ & $6.490 \mathrm{~b}$ & $7.399 \mathrm{a}$ & $5.576 b$ & $5.394 \mathrm{c}$ & $5.142 c$ & $5.950 \mathrm{~b}$ \\
\hline Dezembro & $3.525 \mathrm{c}$ & $4.841 \mathrm{c}$ & $5.346 \mathrm{~b}$ & $4.047 \mathrm{c}$ & $4.500 \mathrm{~d}$ & $3.622 d$ & $4.313 \mathrm{c}$ \\
\hline Janeiro & $1.310 \mathrm{~d}$ & $2.765 \mathrm{~d}$ & $1.532 \mathrm{c}$ & $1.358 \mathrm{~d}$ & $2.510 \mathrm{e}$ & $1.536 \mathrm{e}$ & $1.835 \mathrm{~d}$ \\
\hline Média & $4.765 \mathrm{~B}$ & $5.756 \mathrm{~A}$ & $5.655 \mathrm{~A}$ & $4.769 \mathrm{~B}$ & $5.379 \mathrm{AB}$ & $4.784 \mathrm{~B}$ & \\
\hline \multicolumn{8}{|c|}{ Maior dose ${ }^{(3)}$} \\
\hline Setembro & $7.409 \mathrm{a}$ & $7.804 \mathrm{a}$ & $7.626 \mathrm{a}$ & $7.112 \mathrm{a}$ & $6.653 b$ & $7.259 \mathrm{a}$ & $7.313 \mathrm{a}$ \\
\hline Outubro & $6.467 b$ & $8.181 \mathrm{a}$ & $8.674 \mathrm{a}$ & $5.492 b$ & $7.946 \mathrm{a}$ & $7.431 \mathrm{a}$ & $7.365 \mathrm{a}$ \\
\hline Novembro & $6.018 \mathrm{~b}$ & $7.363 \mathrm{a}$ & $7.594 \mathrm{a}$ & $5.926 \mathrm{~b}$ & $6.055 \mathrm{~b}$ & $6.191 \mathrm{~b}$ & $6.524 \mathrm{~b}$ \\
\hline Dezembro & $3.752 \mathrm{c}$ & $5.433 b$ & $5.404 \mathrm{~b}$ & $4.625 c$ & $4.734 \mathrm{c}$ & $4.024 \mathrm{c}$ & $4.662 \mathrm{c}$ \\
\hline Janeiro & $1.684 \mathrm{~d}$ & $2.855 \mathrm{c}$ & $2.884 \mathrm{c}$ & $1.479 \mathrm{~d}$ & $1.703 \mathrm{~d}$ & $1.352 \mathrm{~d}$ & $1.992 \mathrm{~d}$ \\
\hline Média & $5.066 \mathrm{~B}$ & $6.327 \mathrm{~A}$ & $6.436 \mathrm{~A}$ & $4.926 \mathrm{~B}$ & $5.418 \mathrm{~B}$ & $5.251 \mathrm{~B}$ & \\
\hline
\end{tabular}

(1)Médias seguidas pela mesma letra, minúscula nas colunas e maiúscula nas linhas, não diferem entre si pelo teste de Tukey a $5 \%$ de probabilidade. ${ }^{(2)} 150 \mathrm{~kg} / \mathrm{ha}$ da fórmula $5-20-20+35 \mathrm{~kg} / \mathrm{ha}$ de $\mathrm{N}$ em cobertura. ${ }^{(3)} 300 \mathrm{~kg} / \mathrm{ha}$ da fórmula $5-20-20+70 \mathrm{~kg} / \mathrm{ha} \mathrm{de} \mathrm{N}$ em cobertura.

A correlação significativa $(r=-0,45)$ estimada entre o rendimento de grãos e a severidade da moléstia indicou que a mancha-foliar de Phaeosphaeria esteve linearmente associada a uma redução do rendimento de grãos. Da mesma forma, Sawazaki et al. (1997) obtiveram alta correlação entre a severidade da moléstia e a redução do rendimento de grãos em milho. No entanto, é importante considerar que no presente trabalho outros fatores também foram responsáveis pelo decréscimo no rendimento de grãos com o atraso da semeadura. No sul do Brasil, a semeadura nos meses de setembro e outubro é considerada prioritária para a cultura do milho, principalmente por causa das excelentes condições de radiação solar durante o florescimento e enchimento de grãos (Viégas, 1987). Isso determina decréscimos no rendimento de grãos em semeadura após outubro, principalmente quando não ocorre deficiência hídrica.

\section{Conclusões}

1. O cultivo do milho na Região Sul do Brasil após o mês de outubro apresenta riscos na produtividade, uma vez que a severidade da mancha-foliar de Phaeosphaeria aumenta com o atraso na semeadura.

2. Para semeaduras a partir de novembro, é importante a escolha de híbridos resistentes à PLS; os híbridos AS3466 e o AS3477 podem ser uma opção para a Região Sul, pois apresentam menor severidade de PLS e maior rendimento de grãos.

\section{Referências}

BALMER, E.; PEREIRA, O. A. P. Moléstias no milho. In: PATERNIANI, E.; VIÉGAS, G. P. (Ed.). Melhoramento e produção de milho. Campinas : Fundação Cargill, 1987. p. 597-634.

BEDENDO, I. P. Ambiente e doença. In: BERGAMIN FILHO, A.; KIMATI, H.; AMORIM, L. (Ed.). Manual de fitopatologia. São Paulo : Agronômica Ceres, 1995. p. 331-342.

BRASIL, E. M.; CARVALHO, Y. Comportamento de híbridos de milho em relação a Phaeosphaeria maydis em diferentes épocas de plantio. Pesquisa Agropecuária Brasileira, Brasília, v. 33, n. 12, p. 1977-1981, dez. 1998.

CARSON, M. L. Vulnerability of U. S. maize germplasm to Phaeosphaeria leaf spot. Plant Disease, St. Paul, v. 83, n. 5 , p. 462-464, 1999.

FANTIN, G. M.; SAWAZAKI, E.; BARROS, B. C. Avaliação de genótipos de milho pipoca quanto a resistência a doenças e qualidade da pipoca. Summa Phytopathologica, Jaboticabal, v. 17, n. 2, p. 90-99, 1991.

FERNANDES, F. T.; OLIVEIRA, E. Principais moléstias na cultura do milho. Sete Lagoas : Embrapa-CNPMS, 1997. $80 \mathrm{p}$. 
HUBER, D. M.; McCAY-BUIS, T. S. A multiple component analysis of the take-all disease of cereals. Plant Disease, St. Paul, v. 77, n. 5, p. 437-447, 1993.

MACKENZIE, D. R. Association of potato early blight, nitrogen rate and potato yield. Plant Disease, St. Paul, v. 65, n. 7, p. $575-577,1981$.

MENTEN, J. O. M.; PARADELA, A. L.; MARTINS, L. D. M.; ARANTES, S. R. A. Reação de genótipos de milho à Phaeosphaeria maydis e efeito na produtividade. Revista Ecossistema, São José dos Pinhais, v. 21, p. 7274, 1996.

MOORMAN, G. W. Increased plant mortality caused by Pythium root rot of poinsettia associated with high fertilization rates. Plant Disease, St. Paul, v. 70, n. 2, p. 160-162, 1986.

NAZARENO, N. R. X.; LIPPS, P. E.; MADDEN, L. V. Effect of levels of corn residue on the epidemiology of gray spot of corn in Ohio. Plant Disease, St. Paul, v. 77, n. 1, p. 67-70, 1993.
REIS, E. M.; CASA, R. T. Manual de identificação de moléstias em milho. Passo Fundo : Aldeia Norte, 1996. 80 p.

RITCHIE, S. W.; HANWAY, J. J.; BENSON, G. O. Corn grows. Disponível em: http://www.ag.aistate.edu/ departments/agronomy/corngrows.html. Acesso em: 1999.

SAWAZAKI, E.; DUDIENAS, C.; PATERNIANI, M. E. A. G. Z.; GALVÃO, J. C. C.; CASTRO, J. L.; PEREIRA, J. Reação de cultivares de milho à mancha de Phaeosphaeria no Estado de São Paulo. Pesquisa Agropecuária Brasileira, Brasília, v. 32, n. 6, p. 585-589, jun. 1997.

STEEL, R. G. D.; TORRIE, J. H. Principles and procedures of statistics. New York : McGraw-Hill, 1980. $633 \mathrm{p}$.

VIÉGAS, G. P. Práticas culturais. In: PATERNIANI, E.; VIÉGAS, G. P. (Ed.). Melhoramento e produção de milho. Campinas : Fundação Cargill, 1987. p. 376-428.

WARD, J. M. J.; LAING, M. D.; CAIRNS, A. L. P. Management practices to reduce gray leaf spot of maize. Crop Science, Madison, v. 37, n. 4, p. 1257-1262, 1997. 